\title{
Full-thickness macular hole formation following anti-VEGF injections for neovascular age-related macular degeneration
}

This article was published in the following Dove Press journal:

Clinical Interventions in Aging

26 May 2017

Number of times this article has been viewed

\author{
Stamatina A Kabanarou' \\ Tina Xirou' \\ George Mangouritsas' \\ Christina Garnavou-Xirou ${ }^{2}$ \\ Eirini Boutouri' \\ Ilias Gkizis' \\ Irini Chatziralli ${ }^{3}$
}

'Retina Department, Korgialeneio Benakeio, Hellenic Red Cross Hospital, Athens, Greece; ${ }^{2}$ Retina Department, King's College Hospital, London, UK; ${ }^{3}$ 2nd Department of Ophthalmology, University of Athens, Athens, Greece
Correspondence: Stamatina A Kabanarou Retina Department, Korgialeneio Benakeio Hellenic Red Cross Hospital, I Erithrou Stavrou Street II 26 , Athens, Greece

Tel +30 2l 3206825 I

Email stamatina_k@hotmail.com
Purpose: Macular hole (MH) is part of a group of age-related degenerative diseases characterized by pathology of vitreomacular interface. Similarly, neovascular age-related macular degeneration (nAMD) affects older patients and is a leading cause of irreversible visual loss. The purpose of this case series is to describe the development of full-thickness MH in patients with nAMD, following antivascular endothelial growth factor (anti-VEGF) treatment.

Methods: Participants in this case series were four patients with nAMD, who received antiVEGF injections with variable therapeutic response to treatment. Patients were examined at baseline (when AMD was diagnosed) and monthly thereafter. The examination included visual acuity measurement, slit-lamp biomicroscopy, and optical coherence tomography.

Results: All patients were found to develop full-thickness MH within 1-4 months after the last anti-VEGF injection, even in the absence of pre-existing vitreomacular interface abnormalities in some cases. The median number of injections before the MH formation was 3 .

Conclusion: MH formation may represent an adverse effect of anti-VEGF treatment in patients with nAMD and could be also coexisting pathology with nAMD in older individuals.

Keywords: macular hole, age-related macular degeneration, anti-VEGF

\section{Introduction}

Age-related macular degeneration (AMD) is the leading cause of irreversible visual loss in elderly population in the developed world and its prevalence increases with age, ranging from $0.2 \%$ (for people aged 55-64 years) to 13\% (for those older than 85 years). ${ }^{1-3}$ Neovascular AMD (nAMD) can lead to visual impairment due to the development of choroidal neovascularization (CNV), and its prevalence is estimated to be $0.17 \%-5.8 \% .^{1,3}$ Vascular endothelial growth factor (VEGF) is the main angiogenic factor involved in the pathogenesis of nAMD. ${ }^{4}$ Therefore, over the last two decades, intravitreal anti-VEGF agents are considered the standard of care in $\mathrm{nAMD}$, aiming to block $\mathrm{CNV}$ activity and consequently prevent vision loss and improve vision in some cases. ${ }^{5}$ Specifically, the two FDA-approved anti-VEGF agents for nAMD are ranibizumab (Lucentis ${ }^{\circledR}$; Novartis, Basel, Switzerland), a recombinant antigen-binding fragment that neutralizes all isoforms of VEGF-A, ${ }^{6}$ and aflibercept (Eylea; Bayer Healthcare, Berlin, Germany), which is a recombinant fusion protein consisting of human VEGF receptor extracellular domains from receptors 1 and 2 (VEGFR1 and VEGFR2) fused to the Fc domain of the human IgG backbone and also binded to all isomers of the VEGF-A family, VEGF-B, and placental growth factor. ${ }^{7}$ 
A small number of ocular adverse events $(<1 \%)$ have been reported after administration of anti-VEGF injections across large clinical trials, including endophthalmitis, rhegmatogenous retinal detachment, retinal tear, retinal pigment epithelium tear, traumatic cataract, vitreous hemorrhage, and uveitis. ${ }^{5,8}$ In addition, full-thickness macular hole (FTMH) formation following anti-VEGF treatment for nAMD has sparsely been reported in the literature, mainly as isolated case reports and mostly in the presence of vitreomacular traction disease. ${ }^{9-15}$ In light of the above, the purpose of this case series is to describe the development of FTMH in patients with nAMD, following anti-VEGF injections with variable therapeutic responses to treatment, even in the absence of pre-existing vitreomacular interface abnormalities.

\section{Methods}

Participants in this retrospective case series were four patients with nAMD, who developed FTMH after intravitreal antiVEGF injections. Written informed consent was obtained by all participants for participation in this study and publication of the associated images. This study was in accordance with the Tenets of Helsinki Declaration and was approved by the Institutional Review Board of Korgialeneio Benakeio, Hellenic Red Cross Hospital, Athens, Greece. Exclusion criteria were any of the following: CMV of any cause except nAMD, previous FTMH, vitreomacular traction, uveitis, diabetic retinopathy, glaucoma, or retinal vein occlusion.

At baseline, all patients underwent best-corrected visual acuity (BCVA) measurement by means of Snellen charts, ophthalmic examination including slit-lamp biomicroscopy, and using optical coherence tomography (OCT). Time domain (Stratus 3000; Zeiss, Germany) or spectral domain OCT (Heidelberg Spectralis; Heidelberg Engineering, Heidelberg, Germany) were used. Fluorescein angiography (FA) was performed to confirm diagnosis and to exclude other causes of CNV.

All patients received at least one intravitreal injection of either $0.5 \mathrm{mg}$ ranibizumab or $2.0 \mathrm{mg}$ aflibercept. All the injections were performed under standard sterile conditions. Topical antibiotics were administered to all patients four times a day for 1 day before and for 5 days after the injection. Patients were examined monthly thereafter. At each visit, complete eye examination was performed, including BCVA measurement, fundoscopy, and OCT. FA was performed only at the examiner's discretion and not at every postinjection evaluation.

\section{Results}

The patients' characteristics are shown in Table 1. Of the four patients, two were males and two were females. The mean age of patients was $63.5 \pm 4.5$ years. All patients presented active CNV with subretinal fluid and pigment epithelium detachment (PED). One patient had posterior vitreous detachment (PVD), and in three patients no PVD was present. Two patients had epiretinal membrane (ERM). At baseline, the mean BCVA was 0.4 \pm 0.16 decimal (about 6/12 Snellen). Three patients received ranibizumab and one aflibercept intravitreal injections. All patients developed FTMH about 1-4 months after the last intravitreal injection. Median number of intravitreal injection before developing FTMH was 3. The mean BCVA at the time of FTMH presence was counting fingers in all patients. Figures 1 and 2 showed two indicative cases of our study and their progression over time. No other ocular side effects were found, such as endophthalmitis, inflammation, infection, increased intraocular pressure, retinal tear, or detachment.

\section{Discussion}

According to a recent classification of the vitreoretinal interface disorders, FTMH is an anatomic defect in the fovea featuring interruption of all neural retinal layers from the internal limiting membrane to the retinal pigment epithelium. ${ }^{16}$ Gass $^{17}$ hypothesized that idiopathic FTMH formation occurred due to focal tangential traction on the fovea, following contraction of the prefoveal vitreous cortex. In addition, Gaudric et al ${ }^{18}$ demonstrated with OCT that vitreous traction on the fovea may be oblique, whereas Tanner et $\mathrm{al}^{19}$ suggested that initiation of $\mathrm{MH}$ formation may be attributed to an anteroposterior vitreofoveal traction

Table I Demographic and clinical characteristics of our study sample

\begin{tabular}{lllllllllllll}
\hline Case & Age & Gender & Eye & SRF & PED & PVD & ERM & Injection & $\begin{array}{l}\text { No of } \\
\text { injections }\end{array}$ & $\begin{array}{l}\text { BCVA } \\
\text { before }\end{array}$ & $\begin{array}{l}\text { BCVA } \\
\text { after }\end{array}$ & $\begin{array}{l}\text { Time after } \\
\text { last injection }\end{array}$ \\
\hline I & 66 & Male & Right & Yes & Yes & Yes & No & Ranibizumab & 2 & 0.2 & CF & 2 months \\
2 & 64 & Female & Left & Yes & Yes & No & Yes & Ranibizumab & 3 & 0.4 & CF & 4 months \\
3 & 67 & Male & Right & Yes & Yes & No & Yes & Aflibercept & 3 & 0.4 & CF & I month \\
4 & 57 & Female & Right & Yes & Yes & No & No & Ranibizumab & 3 & 0.6 & CF & I month \\
\hline
\end{tabular}

Abbreviations: BCVA, best corrected visual acuity; CF, counting fingers; ERM, epiretinal membrane; PED, pigment epithelium detachment; PVD, posterior vitreous detachment; SRF, subretinal fluid. 

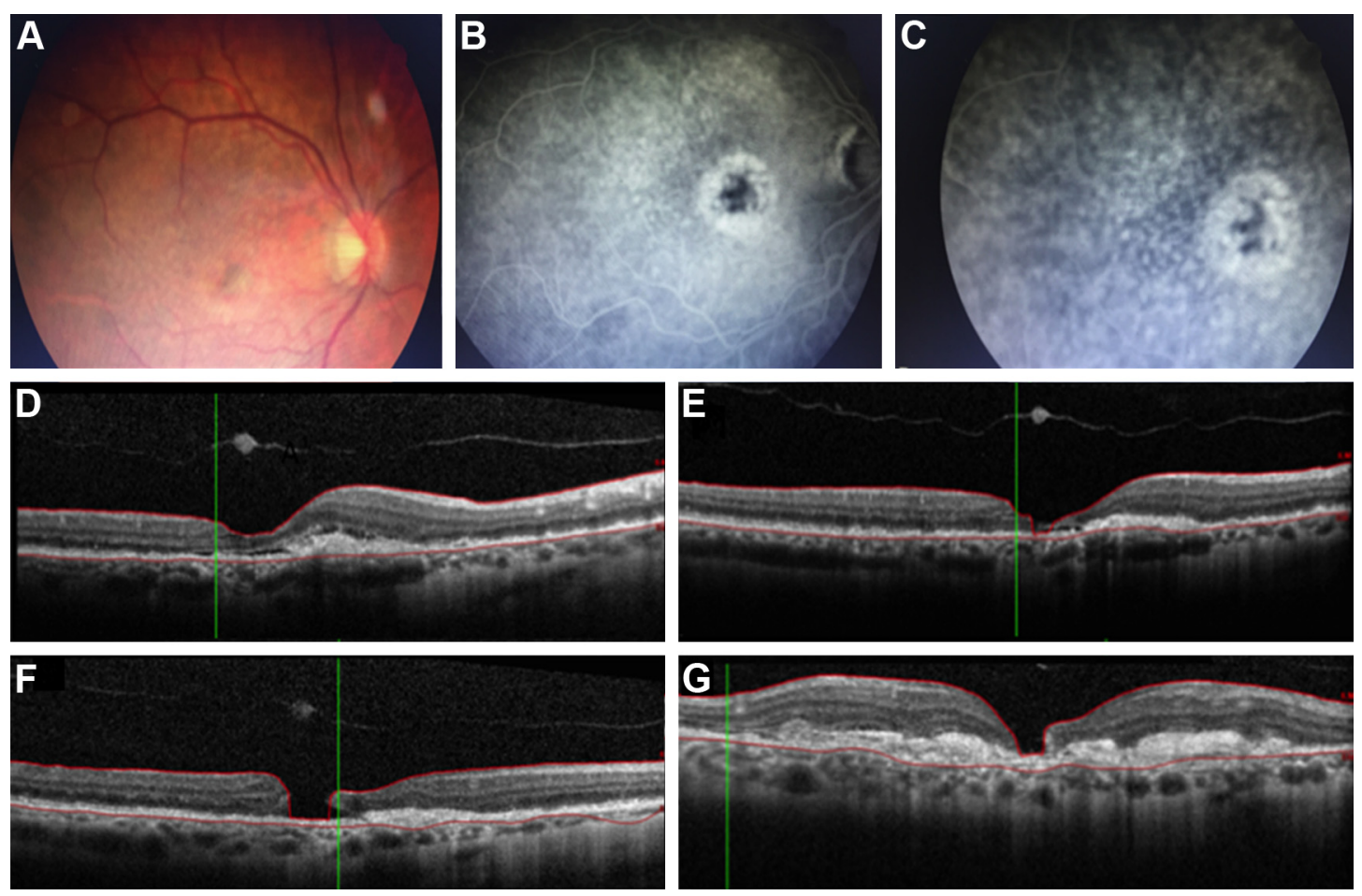

Figure I 66-old-male patient with age-related macular degeneration, who developed full thickness macular hole after ranibizumab injections.

Notes: (A) Color fundus photo in a 66-year-old male patient, demonstrating a pigment epithelium detachment at the fovea surrounded by drusen and few retinal haemorrhages in his right eye; (B) early-phase and (C) late-phase fluorescein angiography of the same patient, showing an active choroidal neovascularization; (D) optical coherence tomography, showing subretinal fluid, pigment epithelium detachment, and retinal pigment epithelium changes, as well as disruption in ellipsoid zone; (E) optical coherence tomography after two ranibizumab injection, showing regression of subretinal fluid; (F) optical coherence tomography 2 months after the last ranibizumab injection, showing full-thickness macular hole; (G) optical coherence tomography 4 months later, showing the development of disciform scar underneath the macular hole, extending beyond the hole's edges.

documented by OCT imaging. Therefore, both tangential and oblique/anterior-posterior transvitreal traction have been implicated in the development of idiopathic FTMH.

The role of abnormal vitreomacular interface in AMD has previously been reported and vitreomacular adhesion, as well as vitreomacular traction has been implicated as potential risk factors for the development of exudative AMD. ${ }^{20,21}$ On the contrary, PVD seemed to have a prophylactic effect on AMD formation. ${ }^{22}$ Furthermore, since currently anti-VEGF agents are the treatment of choice for nAMD, it has been reported that vitreoretinal traction, if present, could antagonize the effect of anti-VEGF treatment and cause pharmacological resistance in patients with nAMD. ${ }^{23}$ However, anti-VEGF intravitreal injections can induce PVD in patients with nAMD. Specifically, it has been reported that $24 \%$ of patients receiving intravitreal injections for exudative maculopathies, such as nAMD, develop PVD over a mean 11.1-week follow-up period and PVD incidence correlates with increasing age. ${ }^{24}$

FTMH formation following intravitreal anti-VEGF treatment for nAMD has been previously reported in the
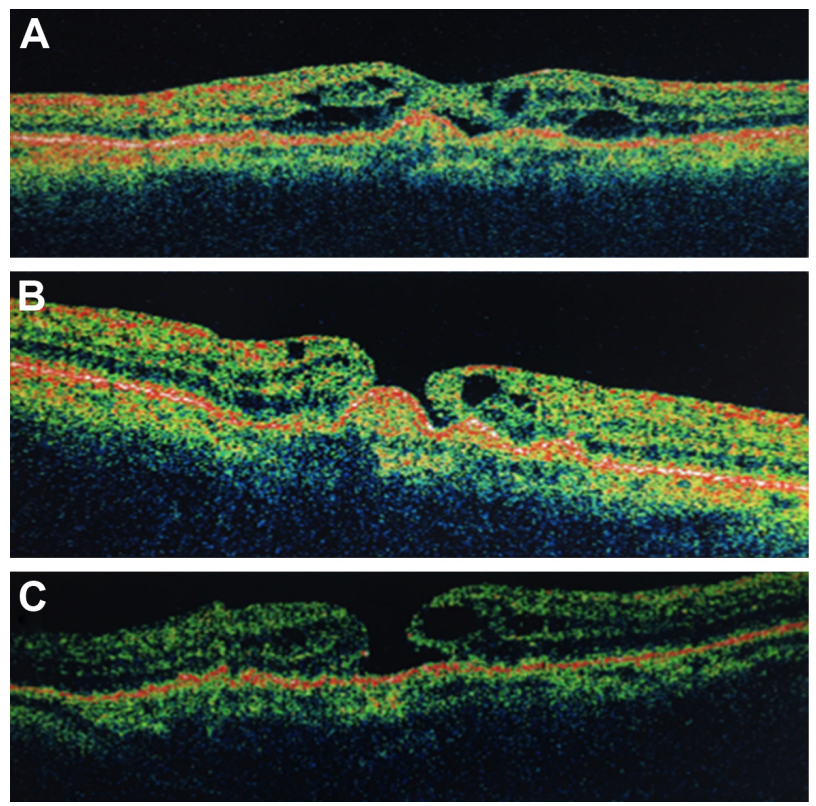

Figure 2 57-year-old female patient who developed full thickness macular hole after ranibizumab injections for age-related macular degeneration.

Notes: (A) Optical coherence tomography of a 57-year-old female patient, showing intraretinal fluid overlying a pigment epithelium detachment; (B) optical coherence tomography I month after three intravitreal ranibizumab injections, showing fullthickness macular hole with the pigment epithelium detachment remaining at the base of the hole; (C) optical coherence tomography 5 months later, showing stability. 
literature but was mainly based on isolated case reports. ${ }^{9-15}$ In all reported cases, vitreomacular interaction forces following intravitreal injections have been speculated to be closely linked to the formation of the MH. Several potential mechanisms have been implicated to explain this process. Induction of vitreous incarceration following anti-VEGF injections could enhance vitreoretinal traction and subsequently FTMH development. ${ }^{13}$ Chemical compounds induced to the vitreous cavity and structural modification of vitreous body following anti-VEGF therapy could also lead to incomplete PVD, vitreomacular traction, and FTMH formation. ${ }^{14,15}$ Grigoropoulos et al hypothesized that intravitreal injections can increase the vitreomacular traction due to globe deformation during needle insertion and vitreous incarceration at the insertion site following treatment. This was proposed to cause vitreous syneresis and increase vitreofoveal traction leading to incomplete PVD and thus, resulting in focal sites of traction on the retinal surface and in FTMH formation. ${ }^{25}$ Moreover, the anti-VEGF agent per se may have caused the $\mathrm{MH}$ by modulating the activity of the $\mathrm{CNV}$ and inducing contraction of the vascular membrane, leading to exacerbation of tangential traction on the overlying retina. ${ }^{10}$

It has also been reported that the presence of PED in nAMD could be a predisposing factor for $\mathrm{MH}$ formation following anti-VEGF treatment. Changes in PED height and size, as a response to anti-VEGF treatment, could enhance the tractional forces exerted on the vitreoretinal interface leading to $\mathrm{MH}$ formation. ${ }^{20}$ It is worthy to mention that all cases in our series had PED, but no retinal pigment epithelium tear developed following anti-VEGF treatment and prior to $\mathrm{MH}$ formation.

In our cases, two patients had only PED and the formation of FTMH in the absence of vitreoretinal interface abnormalities could be attributed to other predisposing factors, such as biochemical or cellular elements, rather than simple mechanical vitreofoveal traction, as previously reported. In the other two cases, a FTMH developed in the presence of a PED, which coexisted with ERM. In fact, a lamellar $\mathrm{MH}$ developed initially, which eventually led to a FTMH formation. Evolution of a lamellar MH to a FTMH could either be the natural course of the disease or could be attributed to the progression of nAMD, even in the absence of further anti-VEGF treatment.

\section{Conclusion}

Taking into account the prevalence of wet AMD as previously reported and the large number of patients treated with
anti-VEGF injections, more attention should be paid on the possible changes of vitreomacular interface and PVD following anti-VEGF injections. If such a relationship exists, then there is a potential risk for $\mathrm{MH}$ formation following antiVEGF treatment. If this risk does exist, it does not outweigh the well-established benefits of anti-VEGF therapy for nAMD. On the other hand, both FTMH and nAMD are age-related conditions with similar prevalence, which increases with age. Therefore, they may represent only coexisting pathologies in the older population and not an adverse effect to anti-VEGF treatment that eventually interact with each other.

\section{Acknowledgment}

This study was presented as a poster at the Controversies in Ophthalmology congress in March 2017, Lisbon.

\section{Disclosure}

The authors report no conflicts of interest in this work.

\section{References}

1. Klein R, Peto T, Bird A, Vannewkirk MR. The epidemiology of agerelated macular degeneration. Am J Ophthalmol. 2004;137(3):486-495.

2. Wong WL, Su X, Li X, et al. Global prevalence of age-related macular degeneration and disease burden projection for 2020 and 2040: a systematic review and meta-analysis. Lancet Glob Health. 2014;2(2):e106-e116.

3. Smith W, Assink J, Klein R, et al. Risk factors for age-related macular degeneration: pooled findings from three continents. Ophthalmology. 2001;108(4):697-704.

4. Adamis AP, Shima DT. The role of vascular endothelial growth factor in ocular health and disease. Retina. 2005;25(2):111-118.

5. Solomon SD, Lindsley K, Vedula SS, Krzystolik MG, Hawkins BS. Antivascular endothelial growth factor for neovascular age-related macular degeneration. Cochrane Database Syst Rev. 2014;8:CD005139.

6. Rosenfeld PJ, Brown DM, Heier JS, et al. Ranibizumab for neovascular age-related macular degeneration. $N$ Engl J Med. 2006;355(14): 1419-1431.

7. Heier JS, Brown DM, Chong V, et al; VIEW 1 and VIEW 2 Study Groups. Intravitreal aflibercept (VEGF trap-eye) in wet age-related macular degeneration. Ophthalmology. 2012;119(12):2537-2548.

8. Day S, Acquah K, Mruthyunjaya P, Grossman DS, Lee PP, Sloan FA. Ocular complications after anti-vascular endothelial growth factor therapy in Medicare patients with age-related macular degeneration. Am J Ophthalmol. 2011;152(2):266-272.

9. Oshima Y, Apte RS, Nakao S, Yoshida S, Ishibashi T. Full thickness macular hole case after intravitreal aflibercept treatment. $B M C$ Ophthalmol. 2015;15:30.

10. Mukherjee C, Mitra A, Kumar NA, Elsherbiny S, Lip PL. Macular hole formation after intravitreal ranibizumab injection in wet age-related macular degeneration. Open Ophthalmol J. 2015;9:177-180.

11. Regatieri CV, Duker JS. Bilateral macular hole after anti-vascular endothelial growth factor therapy in a patient with exudative agerelated macular degeneration. Retin Cases Brief Rep. 2012;6(1): $125-128$.

12. Clemens CR, Holz FG, Meyer CH. Macular hole formation in the presence of a pigment epithelial detachment after three consecutive intravitreal antivascular endothelial growth factor injections. $J$ Ocul Pharmacol Ther. 2010;26(3):297-299. 
13. Querques G, Souied EH, Soubrane G. Macular hole following intravitreal ranibizumab injection for choroidal neovascular membrane caused by age-related macular degeneration. Acta Ophthalmol. 2009; 87(2):235-237.

14. Moisseiev E, Goldstein M, Loewenstein A, Moisseiev J. Macular hole following intravitreal bevacizumab injection in choroidal neovascularization caused by age-related macular degeneration. Case Rep Ophthalmol. 2010;1(1):36-41.

15. Raiji VR, Eliott D, Sadda SR. Macular hole overlying pigment epithelial detachment after intravitreal injection with ranibizumab. Retin Cases Brief Rep. 2013;7(1):91-94.

16. Duker JS, Kaiser PK, Binder S, et al. The International Vitreomacular Traction Study Group classification of vitreomacular adhesion, traction, and macular hole. Ophthalmology. 2013;120(12):2611-2619.

17. Gass JD. Idiopathic senile macular holes: its early stages and pathogenesis. Retina. 2003;23(6 Suppl):629-639.

18. Gaudric A, Haouchine B, Massin P, Paques M, Blain P, Erginay A. Macular hole formation: new data provided by optical coherence tomography. Arch Ophthalmol. 1999;117(6):744-751.

19. Tanner V, Chauhan DS, Jackson TL, Williamson TH. Optical coherence tomography of the vitreoretinal interface in macular hole formation. Br J Ophthalmol. 2001;85(9):1092-1097.
20. Mojana F, Cheng L, Bartsch DU, et al. The role of abnormal vitreomacular adhesion in age-related macular degeneration: spectral optical coherence tomography and surgical results. Am J Ophthalmol. 2008; 146(2):218-227.

21. Schulze S, Hoerle S, Mennel S, Kroll P. Vitreomacular traction and exudative age-related macular degeneration. Acta Ophthalmol. 2008; $86(5): 470-481$.

22. Krebs I, Brannath W, Glittenberg C, Zeiler F, Sebag J, Binder S. Posterior vitreomacular adhesion: a potential risk factor for exudative age-related macular degeneration? Am J Ophthalmol. 2007;144(5):741-746.

23. Veloso CE, Kanadani TM, Pereira FB, Nehemy MB. Vitreomacular interface after anti-vascular endothelial growth factor injections in neovascular age-related macular degeneration. Ophthalmology. 2015; 122(8):1569-1572.

24. Geck U, Pustolla N, Baraki H, Atili A, Feltgen N, Hoerauf H. Posterior vitreous detachment following intravitreal drug injection. Graefes Arch Clin Exp Ophthalmol. 2013;251(7):1691-1695.

25. Grigoropoulos V, Emfietzoglou J, Nikolaidis P, Theodossiadis G, Theodossiadis P. Full-thickness macular hole after intravitreal injection of ranibizumab in a patient with retinal pigment epithelium detachment and tear. Eur J Ophthalmol. 2010;20(2):469-472.
Clinical Interventions in Aging

\section{Publish your work in this journal}

Clinical Interventions in Aging is an international, peer-reviewed journal focusing on evidence-based reports on the value or lack thereof of treatments intended to prevent or delay the onset of maladaptive correlates of aging in human beings. This journal is indexed on PubMed Central, MedLine,

\section{Dovepress}

CAS, Scopus and the Elsevier Bibliographic databases. The manuscript management system is completely online and includes a very quick and fair peer-review system, which is all easy to use. Visit http://www.dovepress. com/testimonials.php to read real quotes from published authors. 